\title{
Management of oesophageal perforation associated with benign stricture and hiatus hernia by oesophagoplasty and fundoplication
}

\author{
DKC COOPER
}

From the Department of Cardiothoracic Surgery, Papworth Hospital, Cambridge

ABSTRACT The operation of oesophagoplasty and Nissen fundoplication has proved valuable in the management of intractable peptic stricture of the oesophagus. This report concerns its use in perforation of the oesophagus in an 81-year-old woman with benign peptic stricture in whom perforation occurred during instrumentation. She made an uneventful recovery from operation and remained well and able to swallow without difficulty at three-month follow-up.

Perforation of the oesophagus is associated with a high morbidity and mortality. Most cases result from instrumentation. ${ }^{1}$ When the oesophagus has been perforated in the presence of a malignant stricture, surgical management entails either resection and drainage of the contaminated tissue spaces, or drainage with or without intubation when the patient's general condition precludes resection. ${ }^{2}$ In benign conditions, closure of the perforation and drainage of the mediastinum is recommended, ${ }^{3-7}$ although intubation has again been advocated as an alternative when the patient's general condition is poor. ${ }^{8}$ Repair of a perforation associated with a distal oesophageal stricture will be followed by breakdown and leakage if the distal obstruction is not completely relieved at the same time. This has been achieved generally by immediate resection. ${ }^{3910}$ Triggiani and Belsey ${ }^{11}$ have recommended that all cases of intrathoracic perforation with gross underlying oesophageal pathology causing stenosis should be treated by exteriorisation and staged reconstruction with the left colon.

Milstein $^{12}$ has reported an operation of oesophagoplasty and intrathoracic Nissen fundoplication for the treatment of intractable peptic stricture of the oesophagus. The operation was used successfully in the management of a patient with this condition in whom a perforation of the oesophagus occurred during instrumentation, the perforation being just proximal to the stricture. Details of the case history and operation are now reported.

Address for reprint requests: Mr DKC Cooper, Department of Cardiothoracic Surgery, Papworth Hospital, Papworth Everard, Cambridge CB3 8RE.

\section{Case history}

The patient was an 81-year-old lady who had had repeated oesophageal dilatations over the previous 15 years for a benign peptic stricture $28 \mathrm{~cm}$ from the incisor teeth, associated with a sliding hiatus hernia. She had last undergone dilatation eight months previously but dysphagia for solids and some fluids had recurred.

At rigid oesophagoscopy on 30 July 1979 the stricture was encountered at $28 \mathrm{~cm}$ as before, and there was severe oesophagitis above it. Dilatation was difficult and resulted in considerable bleeding. After this procedure, the patient complained of severe pain in the right shoulder. A barium swallow showed free flow of barium to the distal half of the thoracic oesophagus where a perforation was demonstrated with tracking of barium into the right pleural space. The perforation was immediately proximal to the oesophageal stricture which itself was just above the hiatus hernia.

A right thoracotomy was performed immediately through the fifth intercostal space. A $1 \mathrm{~cm}$ horizontal tear in the oesophagus was found approximately 4 $\mathrm{cm}$ below the azygos vein. There was a sliding hiatus hernia which extended from the hiatus upwards for approximately $5 \mathrm{~cm}$. The oesophagus with its vagus nerves, which were identified, was mobilised from the azygos vein to the cardia. The fundus and cardia of the stomach were mobilised by division of the short gastric arteries sufficiently to allow the subsequent oesophagoplasty to be performed without tension. A $4 \mathrm{~cm}$ longitudinal incision was made in the oesophagus from the site of perforation distally 
through the fibrous stricture into the stomach. The anaesthetist then passed a large oesophageal tube which was guided by the surgeon down the oesophagus into the stomach. The incision was then closed transversely using a single layer of interrupted sutures of 3/0 Prolene starting at the middle of the vertical incision on both sides and proceeding towards the end. Thus an oesophagoplasty was performed relieving the oesophageal obstruction. The fundus was then wrapped around the lower oesophagus, including the site of the oesophagoplasty, as a Nissen fundoplication. ${ }^{13}$ The large oesophageal tube was removed and replaced by a nasogastric tube. Penicillin and streptomycin powders were applied around the oesophagus and gastric fundus. Two intercostal drainage tubes were inserted and the chest was closed. The patient was given a five-day course of benzylpenicillin, flucloxacillin, and gentamicin beginning at the time of operation. Her postoperative progress was entirely uneventful. The intercostal tubes were removed after two days and the nasogastric tube on the third, by which time she was taking water by mouth. Over the course of the next two days a light diet was introduced, and by the time of her discharge 11 days after operation she was taking a normal diet and had no difficulties in swallowing.

A barium swallow was carried out two days before her discharge. No extravasation of barium was demonstrated and there was free passage through the site of oesophagoplasty into the stomach. She has been seen once as an outpatient three months after operation, remains well, and continues to swallow without difficulty

\section{Discussion}

The operation of oesophagoplasty and Nissen fundoplication has proved of value in the management of intractable peptic stricture of the oesophagus, ${ }^{12}$ but has not been used previously in the management of perforation of the oesophagus. Oesophagoplasty results in repair of the perforation and complete relief of the stricture. Fundoplication prevents further acid reflux and also protects and reinforces the oesophageal suture line, minimising the possibility of any significant leak at this site.

This operation should be considered whenever a perforation results from dilatation of a peptic stricture whether or not the stricture is associated with a hiatus hernia, though this is generally the case. In the absence of a hernia, the oesophageal hiatus can be enlarged, the fundus of the stomach mobilised and brought up into the chest. The procedure may also be of value in any perforation with or without benign stricture, so long as the site of perforation is low enough to allow fundoplication. Repair of the perforation should be performed transversely whenever possible to prevent oesophageal narrowing; covering of the suture line by gastric fundus reinforces it and minimises the risk of leakage at this site.

The same principles of treatment which govern other methods of managing oesophageal perforations are equally applicable to oesophagoplasty and fundoplication. ${ }^{1}$ In particular, early operation is important before gross oedema of the tissues and local infection has occurred, although this operation has also proved successful in a second patient with instrumental perforation at the site of a longstanding stricture proximal to a hiatus hernia even though the operation was not performed until 28 hours after perforation. Thorough toilet of the contaminated tissues, the liberal application of antibiotic powders to this region, drainage of the chest, and a course of intravenous antibiotics resulted in good healing with no infection. However, in general, in patients in whom a delay of more than 24-30 hours has occurred since perforation, the operation is contraindicated, and intubation or resection should be considered instead.

I am indebted to Mr BB Milstein FRCS for permission to publish this case and for advice on its presentation.

\section{References}

${ }^{1}$ Sandrasagra FA, English TAH, Milstein BB. The management and prognosis of oesophageal perforation. Br J Surg $1978 ; 65: 629-32$.

2 Berger RL, Donato AT. Treatment of oesophageal disruption by intubation. Ann Thorac Surg 1972;13:2735.

${ }^{3}$ Groves LK. Instrumental perforations of the oesophagus. What is conservative management? $J$ Thorac Cardiovasc Surg 1966;52:1-10.

- Bertelsen S. Traumatic perforations of the oesophagus. Scand J Thorac Cardiovasc Surg 1971;5:103-11.

${ }^{5}$ Inberg MV, Manner R, Puhakka H. Management of instrumental and spontaneous (atraumatic) perforations of the oesophagus. Scand $J$ Thorac Cardiovasc Surg $1971 ; 5: 61-6$.

${ }^{6}$ Sawyers JL, Lane CE, Foster LH, Daniel RA. Esophageal 음 perforations: an increasing challenge. Ann Thorac Surg $1975 ; 19: 233-8$.

7 Janssen CW. Perforation of the intrathoracic oesophagus. Scand J Thorac Cardiovasc Surg 1976;10:189-92.

${ }^{8}$ Sandrasagra FA, English TAH, Milstein BB. Esophageal N intubation in the management of perforated esophagus $\omega$ with stricture. Ann Thorac Surg 1978;25:399-401.

${ }^{9}$ Kerr WF. Emergency oesophagectomy. Thorax 1968;23:0 204-9.

${ }^{10}$ Kaiser GA, Bowman FO, Wylie RH. Definitive surgery for $\mathbb{E}$ the treatment of oesophageal perforation with distal obstruction. Ann Thorac Surg 1969;8:75-81.

11 Triggiani E, Belsey R. The complications of gastroscopy and oesophagoscopy. Br J Surg 1977;43:396-403.

12 Milstein BB. An operation for the treatment of intractable $\frac{O}{\mathbb{D}}$ peptic stricture of the oesophagus. Israel J Med Sci 1975; 응 11:281-6.

13 Nissen R. Gastropexy and "fundoplication" in surgical treatment of hiatus hernia. Am J Dig Dis 1961;6:954. 